\title{
Determinant Status Migrasi Penduduk di Provinsi Jawa Barat Tahun 2015 Menggunakan Regresi Logistik Multilevel
}

\author{
ATHIYYAH NAFSU'L MUTHMAINNAH ${ }^{1}$, BUDYANRA $^{2}$ \\ ${ }^{1}$ Badan Pusat Statistik - Jakarta \\ 2Jurusan Statistika, Sekolah Tinggi Ilmu Statistik - Jakarta \\ Email: budy@stis.ac.id
}

\begin{abstract}
ABSTRAK
Migrasi merupakan salah satu komponen utama kependudukan selain kelahiran dan kematian. Dari 34 provinsi di Indonesia, Jawa Barat merupakan daerah tujuan utama para migran pada tahun 2015. Namun, persebaran migran di wilayah kabupaten/kota Provinsi Jawa Barat ternyata masih tidak merata terutama pada penduduk berusia 15 tahun ke atas. Hal ini memunculkan adanya dugaan pengaruh wilayah (kontekstual) terhadap status migrasi penduduk. Tujuan penelitian ini untuk mengkaji pengaruh dan kecenderungan variabel-variabel individual dan kontekstual terhadap status migrasi penduduk berusia 15 tahun ke atas. Dari hasil analisis regresi logistik multilevel diketahui variabel-variabel yang memengaruhi status migrasi penduduk berusia 15 tahun ke atas adalah status perkawinan, tingkat pendidikan tertinggi, akses informasi, Tingkat Pengangguran Terbuka (TPT), kepadatan penduduk, dan Upah Minimum Kabupaten/Kota (UMK) dengan kecenderungan karakteristik kawin/pernah kawin, memiliki tingat pendidikan tertinggi lebih dari SMA/K, mendapat akses informasi, menuju daerah dengan TPT yang rendah serta kepadatan penduduk dan UMK yang tinggi. Dengan demikian, sebaiknya pemerintah membuka lapangan pekerjaan dan mengupayakan pemerataan upah serta pemerataan pembangunan agar kesenjangan antarwilayah dapat berkurang.
\end{abstract}

Kata Kunci: Migrasi; Penduduk; Variabel Individual Dan Kontekstual; Regresi Logistik Biner Multilevel; Random Intercept

\section{PENDAHULUAN}

Zopf (1984) menyebutkan bahwa dinamika kependudukan meliputi tiga komponen utama yaitu kelahiran (fertilitas), kematian (mortalitas), dan perpindahan (migrasi). Migrasi merupakan suatu reaksi atas kesempatan ekonomi pada suatu wilayah sehingga dalam konteks demografi memberikan sumbangan yang sangat besar dalam memengaruhi terbentuknya kebijakan kependudukan. Lee, Todaro dan Titus berpendapat bahwa motivasi utama seseorang untuk berpindah adalah motif ekonomi, yang berkembang karena adanya ketimpangan ekonomi antardaerah. Todaro menyebut motif utama tersebut sebagai pertimbangan ekonomi rasional (Mantra, 2000). Hal ini terbukti dengan kondisi umum migrasi penduduk yang akan mengarah pada wilayah yang pembangunan ekonominya lebih baik. Meskipun begitu, dalam mengukur dan menentukan ukuran bagi migrasi itu sendiri sangat rumit karena adanya keterkaitan antara migrasi dan proses pembangunan yang terjadi dalam suatu daerah (Tjiptoherijanto dalam Darmawan \& Chotib, 2007).

Terdapat beberapa faktor yang menyebabkan terjadinya migrasi penduduk, yang salah satunya adalah ketersediaan lapangan pekerjaan pada suatu kabupaten/kota. Secara teori, seharusnya jumlah ketersediaan lapangan pekerjaan menentukan besar migran yang masuk agar jumlahnya sebanding, yang tercermin melalui Tingkat Pengangguran Terbuka (TPT). Semakin rendah TPT daerah tujuan maka jumlah migran yang masuk seharusnya semakin besar, dan sebaliknya. Namun ternyata terdapat keadaan di beberapa daerah di kabupaten/kota Provinsi Jawa Barat yang memiliki ketidaksesuaian dengan teori ini. Pada tahun 2010, keadaan ini paling terlihat di Kota Bekasi yang memiliki persentase TPT sebesar 12,11 persen, yang berada pada peringkat kedelapan, dengan persentase migrasi masuk risen sebesar 12,73 persen, yang berada pada peringkat pertama, dan juga persentase migrasi masuk seumur hidup sebesar 6,11 persen, serta Kota Cimahi yang memiliki persentase TPT sebesar 13,59 persen, yang 


\section{Athiyyah Nafsu'l Muthmainnah, Budyanra}

berada pada peringkat keempat, dengan persentase migrasi masuk risen sebesar 10,74 persen, yang berada pada peringkat keempat, dan juga persentase migrasi masuk seumur hidup sebesar 1,26 persen (BPS, 2012).

Sjaastad, et al. dalam Ezra dan Kiros, 2001 menyebutkan bahwa pembahasan mengenai determinan migrasi biasanya hanya dilakukan pada level makro atau pada level mikro. Padahal model mikroekonomi tradisional dari migrasi menemukan bahwa terdapat hubungan antara individu dengan keadaan wilayahnya. Oleh karena itu, dalam penelitian mengenai status migrasi di Provinsi Jawa Barat ini, peneliti bermaksud mengulas mengenai gambaran umum migrasi dengan fokus pada migran yang paling dominan, yaitu penduduk berusia 15 tahun ke atas dengan menggunakan variabel-variabel berupa karakteristik individu dan wilayahnya (kontekstual). Karena digunakan dua jenis variabel-variabel berdasarkan kondisi individu dan kontekstual, maka penelitian ini akan dilakukan dengan menggunakan metode analisis regresi logistik multilevel.

\section{KONSEP MIGRASI}

Munir (1981) dalam buku "Dasar-Dasar Demografi" menyatakan bahwa migrasi merupakan salah satu dari tiga faktor dasar yang memengaruhi pertumbuhan penduduk, selain kelahiran dan kematian. Migrasi dapat meningkatkan jumlah penduduk apabila jumlah penduduk yang masuk ke suatu daerah lebih banyak daripada jumlah penduduk yang meninggalkan wilayah tersebut. Sebaliknya, migrasi dapat mengurangi jumlah penduduk jika jumlah penduduk yang masuk ke suatu wilayah lebih sedikit daripada jumlah penduduk yang meninggalkan wilayah tersebut. Kajian migrasi secara regional dan lokal sangat penting karena berkaitan dengan kepadatan dan distribusi penduduk yang tidak merata. Menurut hasil Sensus Penduduk yang dilaksanakan sepuluh tahun sekali oleh Badan Pusat Statistik (BPS), ternyata tidak satu provinsi pun di Indonesia yang tidak mengalami migrasi penduduk, baik migrasi masuk maupun migrasi keluar.

Badan Pusat Statistik (BPS) mendefinisikan migrasi sebagai perpindahan penduduk dari satu tempat ke tempat lain, yang terdiri dari tiga jenis, yaitu:

1. Migrasi risen adalah perpindahan penduduk yang terjadi dalam kurun waktu lima tahun terakhir (mulai dari lima tahun sebelum pencacahan). Keterangan ini diperoleh dari pertanyaan tempat tinggal lima tahun yang lalu dan tempat tinggal sekarang. Jika kedua tempat berlainan maka dikategorikan sebagai migran risen yang juga merupakan bagian dari migrasi total, hanya saja waktunya dalam kurun lima tahun terakhir.

2. Migrasi seumur hidup adalah perpindahan penduduk yang terjadi dari tempat lahir ke tempat tinggal sekarang tanpa melihat kapan pindahnya. Dalam teori ini migrasi diperoleh dari keterangan tempat lahir dan tempat tinggal sekarang, jika kedua keterangan ini berbeda maka termasuk migrasi semasa hidup.

3. Migrasi total adalah perpindahan penduduk yang terjadi sehingga menyebabkan tempat tinggal sebelumnya berbeda dengan tempat tinggal sekarang. Keterangan ini diperoleh dari tempat tinggal sebelumnya dan tempat tinggal sekarang. Ada kemungkinan tempat tinggal sebelumnya sama dengan tempat lahir dan ada juga kemungkinan tidak sama sehingga migrasi semasa hidup termasuk migrasi total.

Menurut Lewis dan Todaro (dalam Saepudin, 2007) menyebutkan bahwa terdapat beberapa hal penting penyebab migrasi, antara lain:

1. Adanya perbedaan tingkat upah antarsektor dan antarwilayah.

2. Adanya pengaruh kinerja investasi di sektor manufaktur perkotaan yang bisa dilihat dari share sektor industri pengolahan.

3. Peluang terciptanya sektor informal di perkotaan.

4. Kemungkinan mendapatkan pekerjaan di perkotaan.

5. Efek dari kebijakan upah minimum yang ditetapkan oleh pemerintah. 


\title{
3. VARIABEL - VARIABEL YANG MEMENGARUHI STATUS MIGRASI PENDUDUK BERUSIA 15 TAHUN KE ATAS
}

\author{
Jenis Kelamin
}

Ravenstein menjelaskan bahwa salah satu Laws of Migration menyatakan bahwa perempuan cenderung untuk melakukan migrasi pada jarak dekat, sementara laki-laki cenderung untuk melakukan migrasi pada jarak yang lebih jauh (Lee, 1966). Migran laki-laki pada umumnya lebih bebas untuk memilih daerah tujuan. Bila migran laki-laki berhasil maka akan menjadi kebanggaan bagi masyarakat daerah asal. Sebaliknya keberhasilan migran perempuan kadangkadang tidak dinilai secara wajar. Kondisi itu menyebabkan kesempatan perempuan untuk bermigrasi menjadi lebih terbatas dibandingkan dengan laki-laki (Abdullah, 1996).

\section{Status Perkawinan}

Jacob Mincer dalam penelitiannya yang berjudul "Family Migration Decision", yang dimuat dalam Jurnal of Political Economy, Oktober 1978, seperti yang dikutip oleh McConnell dan Brue (1995) menemukan bahwa orang yang tidak kawin cenderung lebih mobile daripada yang sudah kawin. Sedikit bertolak belakang dengannya, Kacques Ledent (1990) (dalam Saepudin, 2007), dengan menggunakan hasil dari Sensus Kanada tahun 1981 menemukan bahwa orang yang cerai hidup lebih mobile daripada orang yang berstatus kawin atau cerai mati. Selain itu ia juga menemukan bahwa penduduk yeng berstatus kawin pada umur-umur muda cenderung lebih mobile.

\section{Tingkat Pendidikan Terakhir}

Abdullah (1996) dalam penelitiannya menyebutkan bahwa semakin tinggi tingkat pendidikan biasanya mutu sumber daya manusianya juga semakin baik. Hal ini meningkatkan kemungkinan untuk memperoleh pekerjaan sehingga mendorong terjadinya migrasi. Hal ini sejalan dengan pendapat dalam penelitian sebelumnya yang dikatakan oleh Connel,1976 (dikutip oleh Mantra, 1995) bahwa orang berpendidikan cenderung untuk berpindah, sementara yang tidak berpendidikan cenderung untuk tetap tinggal di rumah. Hani Laksono dan Eko Budi Santoso pada tahun 2012 melakukan penelitian mengenai karakteristik migran dan menyimpulkan bahwa migrasi cenderung terjadi pada penduduk dengan pendidikan terakhir berupa Sekolah Menengah Atas (SMA).

\section{Akses Informasi}

Ehrenberg (2012) menyatakan bahwa salah satu faktor yang memengaruhi terjadinya migrasi adalah adanya akses terhadap informasi. Hal ini dibuktikan oleh Megumi Muto (2010) yang menyebutkan dalam penelitiannya bahwa akses terhadap informasi yang semakin baik, baik melalui jaringan personal ataupun teknologi seperti telepon genggam, dapat mengurangi biaya untuk mencari pekerjaan dan hal tersebut dapat mendorong terjadinya migrasi. Peningkatan akses terhadap informasi melalui telepon genggam secara potensial juga ikut meningkatkan migrasi dari daerah desa ke daerah kota melalui penyediaan informasi mengenai pekerjaan bagi orang di daerah desa.

\section{Tingkat Pengangguran Terbuka (TPT)}

Angka pengangguran di daerah tujuan yang rendah akan mengundang migran untuk datang ke daerah tersebut. Hal ini disebabkan karena adanya indikasi tersedianya lapangan pekerjaan yang cukup sehingga migran yang datang ke daerah tersebut akan memperoleh pekerjaan dalam waktu yang relatif singkat (Mazek, 1966; Glantz, 1973; Bellante \& Jackson, 1983 dalam Dohar, 1999).

\section{Kepadatan Penduduk}

Tingkat kepadatan penduduk yang tinggi di suatu wilayah tentu dapat memberikan efek negatif melalui tekanan populasi terhadap sumber daya yang langka seperti lahan pertanian, namun 
kepadatan penduduk yang tinggi juga dapat berkaitan dengan intensitas aktivitas ekonomi yang tinggi juga melalui aglomerasi ekonomi (Fujita, Krugman, \& Venables, 1999). Sehingga secara tidak langsung, kepadatan penduduk yang tinggi di daerah kota akan memicu terjadinya urbanisasi secara terus menerus. Yanyan Liu dan Fatoshi Yamauchi menyimpulkan dalam penelitian mereka yang dilaksanakan pada tahun 2013, bahwa meskipun daerah kota memiliki tingkat kepadatan penduduk yang lebih tinggi, namun daerah tersebut tetap saja dapat menarik penduduk yang berasal dari daerah desa sehingga menyebabkan tejadinya urbanisasi yang terus menerus. Artinya, tingkat kepadatan penduduk di suatu daerah akan mejadi pertimbangan dalam melakukan migrasi karena memungkinkan adanya indikasi bahwa semakin padat suatu daerah, maka aktivitas ekonomi yang tersedia juga semakin banyak.

\section{Upah Minimum Kabupaten/Kota (UMK)}

Pendapat Lewis dan Todaro (dalam Saepudin, 2007) menyebutkan bahwa salah satu hal penting yang menyebabkan terjadinya migrasi adalah efek dari kebijakan upah minimum yang ditetapkan oleh pemerintah. Hia (2015) dalam penelitiannya mengenai migrasi neto tenaga kerja (yang didefinisikan sebagai penduduk berusia 15 tahun ke atas) menyatakan bahwa Upah Minimum Kabupaten/Kota (UMK) merupakan salah satu variabel yang berpengaruh terhadap perpindahan penduduk. Artinya, semakin tinggi upah minimum yang ditawarkan oleh suatu daerah maka kecenderungan penduduk untuk mempertimbangkannya sebagai salah satu alasan untuk bermigrasi menuju daerah tersebut juga semakin besar.

\section{ANALISIS REGRESI LOGISTIK BINER}

Hosmer dan Lemeshow (1989) menyebutkan bahwa metode regresi merupakan suatu komponen integral dari analisis data yang menjelaskan hubungan antara variabel respons yang berskala kategorik dengan satu atau lebih variabel penjelas yang dapat bersifat kategorik ataupun kontinyu. Lebih dari sepuluh tahun belakangan, model regresi logistik menjadi metode analisis baku yang umum digunakan dalam berbagai bidang. Apabila variabel respons yang dihasilkan berupa dua kategori, maka jenis analisis regresi logistik yang digunkan adalah analisis regresi logistik biner. Data berskala kategorik dihasilkan dari suatu percobaan identik yang menghasilkan dua jenis respons, yaitu sukses atau gagal dimana peluang untuk sukses di tiap percobaan adalah sama dan antar nilai respons yang dihasilkan tidak saling memengaruhi (independent).

\section{ANALISIS MULTILEVEL}

Data berstruktur hierarki adalah data yang muncul karena adanya individu-individu yang terkumpul/tersarang dalam kelompok-kelompoknya masing-masing (Goldstein, 1995). Artinya, unit-unit pada data berstruktur hierarki yang diobservasi pada kelompok yang sama umumnya memiliki karakteristik yang hampir sama dibandingkan dengan unit-unit lain yang diobservasi pada kelompok yang berbeda. Sehingga korelasi antar unit-unit dalam kelompok yang sama akan kuat, atau dengan kata lain dapat dikatakan bahwa data berstruktur hierarki tidak sepenuhnya independen. Oleh karena itu analisis regresi logistik biner kurang tepat untuk digunakan (Hox, 2010).

Penelitian di bidang sosial biasanya melibatkan masalah yang menghubungkan antara individu dengan lingkungan atau kelompoknya. Konsep umumnya adalah individu berinteraksi dengan kelompok sosial di sekitarnya, sehingga individu tersebut dipengaruhi oleh kelompok sosialnya, dan kelompok tersebut juga dipengaruhi oleh individu-individu yang ada di dalam kelompok tersebut. Hal ini mengarahkan pada penelitian dengan menggunakan pendekatan secara individu dan kelompok, yang dapat diakomodasi dengan menggunakan analisis multilevel (Hox,2010).

Goldstein (1995) memperkenalkan model regresi multilevel yang bertujuan untuk mengatasi masalah pada data yang berstruktur hierarki. Data berstuktur hierarki muncul karena adanya individu-individu yang terkumpul/tersarang dalam kelompok-kelompok sosialnya masingmasing. Analisis multilevel ini sangat cocok diterapkan pada data berkelompok atau data dengan klaster serta pada kasus data yang diperoleh dari penarikan sampel multitahap (Goldstein, 1995). Kish (1995) mengatakan bahwa suatu survei yang dilakukan dengan penarikan sampel secara bertahap sebenarnya memiliki efek dari kelompok yang membawahi elemen yang diteliti atau efek dari klaster yang disebut dengan design effect dan ditunjukkan 
oleh nilai interclass correlation. Analisis ini melakukan pengamatan, pengukuran, dan analisis variabel pada berbagai level secara bersamaan sehingga penelitian yang mempertimbangkan hubungan antara karakteristik individu dan karakteristik kelompoknya merupakan jenis penelitian yang dapat dianalisis dengan menggunakan analisis multilevel (Hox, 2010).

Hox (2010) menyontohkan data berstruktur hierarki digunakan dalam penelitian pada bidang pendidikan dimana populasi terdiri sekolah-sekolah dan murid-murid yang ada di masingmasing sekolah tersebut.prosedur penarikan sampel dalam penelitian ini terdiri dari dua tahap: pertama, beberapa sampel ditarik dari sekolah-sekolah tersebut, lalu kemudian sampel murid ditarik dari murid-murid yang ada pada sekolah-sekolah yang terpilih sebagai sampel pada contoh ini, murid-murid bersarang pada sekolahnya.

Dengan adanya indikasi bahwa data yang dianalisis berasal dari beberapa level dan berstruktur hierarki, maka model multilevel merupakan salah satu bentuk dari model regresi campuran (linear mixed models) yang menggabungkan antara efek tetap (fixed effects) dan efek random (fixed effects) ke dalam suatu persamaan.

\section{REGRESI LOGISTIK BINER MULTILEVEL}

Analisis regresi logistik biner multilevel digunakan karena variabel respons dibagi menjadi dua kategori yaitu melakukan migrasi dan tidak melakukan migrasi dengan variabel penjelasnya berstruktur hierarki. Interpretasi parameter pada analisis regresi logistik biner multilevel tidak berbeda dengan analisis regresi logistik biner satu level. Namun, dalam analisis regresi logistik biner multilevel dilakukan estimasi terhadap komponen varian. Varian antarkelompok menunjukkan adanya efek dari unit-unit pada level 2 terhadap unit level 1. Efek ini disebut sebagai efek acak (random effect).

Penelitian multilevel akan membagi modelnya menjadi dua yaitu null model dan conditional model. Null model merupakan kondisi dimana variabel penjelas belum dimasukkan ke dalam model, baik variabel penjelas pada level 1 maupun pada level 2. Sementara itu, conditional model merupakan kondisi dimana variabel penjelas, baik variabel penjelas pada level 1 maupun pada level 2, sudah dimasukkan ke dalam model. Sehingga pada kondisi inilah model dapat juga disebut dengan model regresi logistik biner multilevel.

Hox (2010) menyebutkan bahwa model regresi multilevel dapat digolongkan menjadi dua bentuk dasar, yaitu:

1. Model multilevel dengan random intercept

Model ini merupakan model dimana intercept dimodelkan sebagai random effect dari variabel pada level 2 dengan asumsi bahwa setiap kelompok memiliki intercept yang berbeda-beda (tidak fixed seperti regresi biasa), namun memiliki kemiringan atau slope yang sama sehingga pengaruh setiap variabel penjelas terhadap variabel respons sama untuk tiap-tiap kelompok.

2. Model multilevel dengan random slope

Model ini merupakan model dimana koefisien variabel-variabel penjelas pada level yang lebih rendah dimodelkan sebagai random effect dari variabel pada level 2 dengan asumsi bahwa tiap kelompok memiliki kemiringan atau slope yang berbeda-beda (tidak fixed seperti regresi biasa) sehingga memungkinkan pengaruh variabel penjelas terhadap variabel respons berbeda-beda untuk tiap kelompok.

Pada penelitian ini, model yang digunakan adalah model multilevel dengan random intercept karena mengasumsikan pengaruh setiap variabel penjelas terhadap variabel respons adalah sama untuk setiap kelompok.

\section{MODEL MULTILEVEL LOGISTIK BINER DUA LEVEL DENGAN RANDOM INTERCEPT MODEL}

Random intercept model merupakan salah satu bentuk model regresi dua level (biner) dimana perpotongan (intercept) pada model terhadap sumbu $y$ dinyatakan dalam bentuk random (tidak fixed seperi pada regresi linier biasa). Intercept yang berbeda-beda untuk tiap unit pada level 2 dapat digunakan untuk mengukur perbedaan karakteristik antar unit pada level 2. Jika digambarkan dalam bentuk grafik, random intercept model adalah sebagai berikut: 


\section{Athiyyah Nafsu'l Muthmainnah, Budyanra}

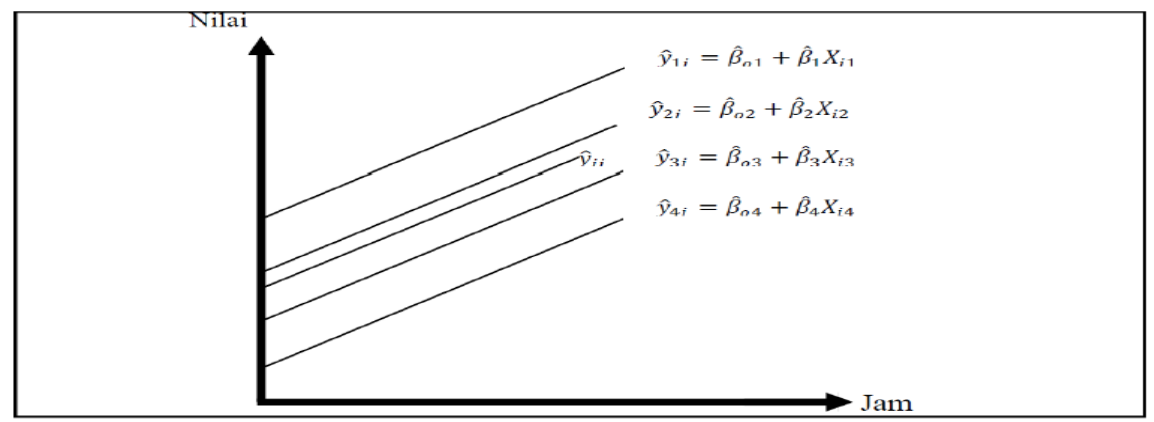

Gambar 1. Random intercept model pada analisis regresi multilevel

Variabel respons yang digunakan dalam penelitian ini berupa variabel diskrit dengan dua kategori, dimana variabel respons tidak berdistribusi normal. Distribusi yang digunakan oleh variabel respons dua kategori adalah salah satu bentuk distribusi keluarga eksponensial, yaitu binomial. Untuk mengatasi distribusi data yang tidak normal ini digunakan generalized linear model. Menurut Agresti (2002), generalized linear model memiliki tiga komponen, yaitu:

1. Random component

Random component GLM terdiri dari variabel tidak bebas Y dengan observasi independen $\left(y_{1} \times y_{2} \times y_{N}\right)$ dari suatu distribusi keluarga eksponensial. Keluarga eksponensial tersebut memiliki fungsi kepadatan peluang atau mass function dengan bentuk:

\section{Systematic component}

$$
f\left(y_{i}, \theta_{i}\right)=a\left(\theta_{i}\right) b\left(y_{i}\right) \exp \left[y_{i} Q\left(\theta_{i}\right)\right]
$$

Systematic component GLM menghubungkan vektor $\eta^{s}=\eta_{1} \ldots \eta_{n}$ dengan variabel bebas melalui sebuah model linier. Misalkan $x_{i j}$ didefinisikan sebagai nilai prediktor $k(k=1,2, . ., p)$ untuk subjek-i. Sehingga:

\section{Link function}

$$
\eta_{i}=\sum_{i} \beta_{k} x_{i k}, i=1,2, \ldots, n
$$

Link function merupakan fungsi yang menghubungkan random component dan systematic component. Misalkan $\mu_{i}=E\left(Y_{i}\right), i=1,2, \ldots, n$. Model menghubungkan $\mu_{i}$ ke $\eta_{i}$ dengan $\eta_{i}=g\left(\mu_{i}\right)$ di mana link function $g$ monoton, fungsi yang dapat didiferensialkan. Oleh karena itu, $g$ terhubung ke $E\left(Y_{i}\right)$ melalui formula:

$$
g\left(\mu_{i}\right)=\sum_{i} \beta_{k} x_{i k}, i=1,2, \ldots, n
$$

Link function $g\left(\mu_{\mathrm{i}}\right)=\mu$ disebut sebagai identity link, di mana $\mu_{i}=\eta_{\mathrm{i}}$

Secara umum, model multilevel logistik biner dengan random intercept model dapat dituliskan sebagai berikut:

$$
\eta=\beta_{o j}+\sum_{p=1}^{p} \beta_{p j} X_{p i j}+\varepsilon_{i j}
$$

maka inverse fungsi logit untuk data dengan variabel respons binomial didefinisikan sebagai berikut:

$$
\pi_{i j}=F(\eta)=\frac{e^{\eta}}{\left(1+e^{\eta}\right)}
$$

dimana $e$ menunjukkan fungsi eksponensial, $F(\eta)$ merupakan transformasi logistik dari $\eta$. Persamaan baru dengan $\eta$ berada di sisi kanan sebagai bentuk lain dari generalized linear model adalah sebagai berikut:

$$
\ln \left[\frac{\pi_{i j}}{1-\pi_{i j}}\right]=\eta=\beta_{0 j}+\sum_{p=1}^{p} \beta_{p j} X_{p i j}+\varepsilon_{i j}
$$

Intercept dalam random intercept model diasumsikan bervariasi antar kelompok. Variasi ini dimodelkan oleh variabel $\boldsymbol{Z}_{j}$ pada level 2 dengan persamaan sebagai berikut: 
dimana:

$$
\ln \left[\frac{\pi_{i j}}{1-\pi_{i j j}}\right]=\eta=\gamma_{00}+\sum_{p=1}^{p} \gamma_{p o} X_{p i j}+\sum_{q=1}^{Q} \gamma_{0 q} Z_{q j}+U_{0 j}+\varepsilon_{i j}
$$

$\gamma_{00}=$ intercept, merupakan rata-rata secara keseluruhan,

$\gamma_{\text {po }}=$ efek tetap untuk variabel penjelas ke-p (fixed slope) dimana $p=1,2, \ldots, P$,

$X_{\text {pij }}=$ variabel penjelas ke- $p$ pada level 1 untuk individu ke- $i$ pada level 1 dalam kelompok ke- $j$ pada level 2 dimana $p=1,2, \ldots, P$,

$Z_{\text {q j }}=$ variabel penjelas ke- $q$ pada level 2 untuk kelompok ke- $j$ dimana $q=1,2, \ldots, Q$,

$U_{0 j}=$ efek random kelompok ke-j pada level 2 ,

$\varepsilon_{i j}=$ residual untuk individu ke- $i$ pada level 1 dalam kelompok ke- $j$ pada level 2.

Berdasarkan persamaan umum di atas, maka model untuk penelitian ini adalah sebagai berikut:

Level 1 (Individu)

$$
\ln \left[\frac{\pi_{i j}}{1-\pi_{i j}}\right]=\beta_{0 j}+\beta_{i j} \mathrm{~J}+\beta_{2 j} \text { SKawin }+\beta_{3 j} \text { Pendidikan }+\beta_{4 j} \text { AksInfo }+\varepsilon_{i j}
$$

Level 2 (Kabupaten/Kota)

$$
\beta_{0 j}=\gamma_{00}+\gamma_{01} T P T+\gamma_{02} \text { Kepadatan }+\gamma_{03} U M K+U_{0 j}
$$

keterangan: $\beta_{1 j}=\gamma_{10^{3}} \beta_{2 j}=\gamma_{20^{j}} \beta_{a j}=\gamma_{a 0^{j}} \beta_{4 j}=\gamma_{40}$

Merujuk pada kedua persamaan di atas, maka model multilevel logistik biner dengan random intercept yang terbentuk adalah sebagai berikut:

$\ln \left[\frac{\pi_{i j}}{1-\pi_{i j}}\right]=\gamma_{00}+\gamma_{10} J K+\gamma_{20}$ SKawin $+\gamma_{a 0}$ Pendidikan $+\gamma_{40}$ AksInf $+\gamma_{01} T P T+\gamma_{02}$ Kepadatan
$+\gamma_{03} U M K+U_{0 j}+\varepsilon_{i j}$

\section{TAHAPAN DALAM REGRESI LOGISTIK BINER MULTILEVEL}

\section{Pengujian Signifikansi Random Effect (Likelihood Ratio Test)}

Prosedur maximum likelihood estimator mampu menghasilkan suatu statistik yang disebut deviance yang mampu mengindikasikan seberapa cocok model dengan data (Hox, 2010). Model dengan deviance yang lebih rendah akan lebih fit dibandingkan dengan model yang deviancenya lebih tinggi. Pada model bersarang (berhierarki), tes deviance dapat digunakan untuk mengetahui apakah model yang lebih umum lebih baik digunakan daripada model sederhana atau apakah model dengan efek random lebih baik daripada model tanpa efek random. Pengujian deviance membandingkan nilai -2 log likelihood yang diperoleh dari setiap model yang diestimasi yaitu model tanpa efek random dan model dengan efek random dimana efek random yang dimaksud merupakan efek yang disebabkan variasi antarkelompok (level 2). Perbedaan varians atau ragam untuk dua model bersarang memiliki distribusi chi-kuadrat, dengan derajat kebebasan sama dengan perbedaan jumlah parameter yang diestimasi dalam dua model.

Pengujian dilakukan dengan hipotesis :

$\mathrm{H}_{0} \quad: \sigma_{\text {uo }}^{2}=0$ (efek random tidak signifikan)

$\mathrm{H}_{1} \quad: \sigma_{\mathrm{uo}}^{2} \neq 0$ (efek random signifikan)

Statistik uji :

LR $=-2 \ln \left(\frac{\text { Likelihood model logistik tanpa efekrandom }}{\text { Likelihood model logistik dengan efekrandom }}\right)$ 


\section{Athiyyah Nafsu'l Muthmainnah, Budyanra}

Tolak Ho jika LR $>\chi_{(\alpha, D)}^{2}$ dimana v adalah selisih jumlah parameter dari kedua model. Ho ditolak maka dpat disimpulkan bahwa efek random signifikan. Artinya terdapat keragaman atau variasi variabel respons yang signifikan antarkelompok sehingga model multilevel lebih baik dalam menjelaskan data daripada model logistik biasa.

\section{Interclass Corelation Coefficient (ICC)}

Interclass Correlation Coefficient (ICC) digunakan untuk mengukur variasi (keragaman) variabel respons yang dapat dijelaskan oleh adanya perbedaan karakteristik antarkelompok atau melihat korelasi unit-unit di dalam kelompok yang sama (Hox,2010). Semakin besar nilai ICC, maka antarunit level 1 akan semakin homogen sedangkan antarunit level 2 akan semakin heterogen.

Dalam model dua level, model yang digunakan untuk mengestimasi intraclass correlation adalah model yang tidak mengandung variabel penjelas, yaitu model intercept only. Model menguraikan varians menjadi dua komponen independen, yaitu $\hat{\sigma}_{\varepsilon}^{2}$ yang merupakan varians pada error level terendah $\mathrm{e}_{\mathrm{ij}}$ yang bernilai fixed sebesar $\Pi^{2} / 3 \approx 3,29$ dan $\hat{\sigma}_{\mathrm{wo}}^{2}$ yang merupakan varians pada error level tertinggi uoj. Dengan menggunakan model ini, intraclass correlation dapat didefinisikan sebagai :

$$
\mathrm{ICC}=\frac{\vec{\sigma}_{10}^{2}}{\sigma_{100}^{2}+\vec{\sigma}_{2}^{2}}
$$

ICC di atas 0,05 atau 5\% mengindikasikan bahwa variasi antar kelompok lebih besar daripada yang diharapkan dan mengimplikasikan bahwa penyarangan pada kelompok-kelompok memiliki efek pada respons yang diberikan oleh individu-individu di dalamnya sehingga analisis multilevel diperlukan (Sorra dan Dyer, 2010)

\section{Estimasi Parameter}

Metode estimasi yang digunakan untuk generalized linear model adalah maximum likelihood estimation (MLE) dimana metode ini biasanya menghasilkan estimasi yang efisien dan konsisten. MLE mempunyai prinsip memaksimumkan fungsi likelihood dengan menggunakan inverse dari link function untuk memprediksi variabel respons. Keuntungan penggunaan maximum likelihood estimator adalah menghasilkan estimasi yang lebih efisien dan konsisten (Agresti,2002). Prosedur MLE dalam pemodelan multilevel dihasilkan dari proses iterasi yang dimulai dengan nilai parameter perkiraan yang akan meningkat dalam setiap iterasi berturutturut sehingga nilai parameter akan berubah selama proses iterasi.

\section{Pengujian Signifikansi Parameter Secara Simultan (Uji G)}

Pengujian parameter secara simultan dilakukan untuk mengetahui pengaruh variabel penjelas di dalam model terhadap variabel respons secara bersama-sama. Pengujian ini dapat dilakukan dengan menggunakan hipotesis:

$$
\begin{aligned}
& \mathrm{H}_{0}: \gamma_{10}=\gamma_{20}={ }^{m}=\gamma_{p 0}=\gamma_{01}={ }^{m}=\gamma_{00}=0 \\
& \text { (tidak ada pengaruh variabel penjelas terhadap variabel respons) } \\
& \mathrm{H}_{1} \quad: \text { minimal ada } \gamma \neq 0
\end{aligned}
$$

(minimal ada satu variabel penjelas yang berpengaruh terhadap variabel respons)

Dengan menggunakan statistik uji G (Hosmer \& Lemeshow, 1989) :

$$
\mathrm{G}=-2 \ln \left(\frac{\text { Likelihood tanyavariabel penjelas (null model) }}{\text { Likelithood dengan variabel penjelas (conditional model) }}\right)
$$

G berdistribusi $\chi_{(\alpha, n)}^{2}$ dimana derajat bebas $p$, dimana $p$ adalah variabel penjelas yang berada pada level 1 dan level 2. Ho ditolak apabila nilai $\mathrm{G}>\chi_{(\alpha n)}^{2}$. Ketika Ho ditolak, maka dapat disimpulkan bahwa pada tingkat kepercayaan (1-a) persen, paling tidak ada satu variabel penjelas didalam model yang memengaruhi variabel respons 


\section{Pengujian Signifikasi Parameter Secara Parsial (Uji Wald)}

Hox (2010) menyebutkan bahwa pengujian secara parsial bertujuan untuk mengetahui signifikansi dari masing-masing parameter yang terdapat dalam model dengan menggunakan hipotesis:

$\mathrm{H}_{0}: \gamma_{p q}=0$ (tidak ada pengaruh variabel penjelas ke- $p$ pada level 1 atau variabel penjelas ke- $q$ pada level 2 terhadap variabel respons)

$\mathrm{H}_{1}: \gamma_{p q} \neq 0$ (terdapat pengaruh variabel penjelas ke- $p$ pada level 1 atau variabel penjelas ke- $q$ pada level 2 terhadap variabel respons)

Dengan menggunakan statistik uji W:

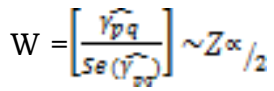

W berdistribusi normal, sehingga $\mathrm{H}_{0}$ ditolak jika $|\mathrm{W}|>Z_{\text {tabel }}$ atau $p$-value $<$ a. Apabila $\mathrm{H}_{0}$ ditolak, dapat disimpulkan bahwa variabel penjelas signifikan berpengaruh terhadap variabel respons.

\section{Penghitungan Odds Ratio (OR)}

Interpretasi parameter dilakukan dengan menggunakan nilai odds ratio. Odds ratio adalah perbandingan risiko terjadinya suatu event dari suatu kelompok/kategori yang satu terhadap kelompok / kategori yang lain. Odds ratio memperkirakan bagaimana kecenderungan terjadinya suatu kejadian sukses antara observasi $\mathrm{x}=1$ dibandingkan dengan observasi $\mathrm{x}=2$ (Hosmer dan Lemeshow, 2000). Persamaan odds ratio adalah sebagai berikut :

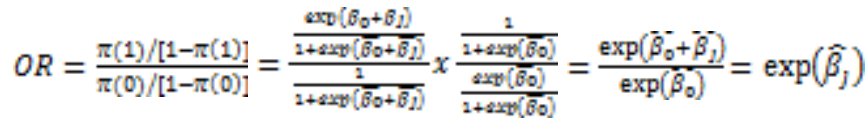

Interpretasi dari OR adalah resiko kecenderungan terjadinya peristiwa $\mathrm{y}=1$ adalah sebesar $\exp \left(\beta_{j}\right)$ kali resiko atau kecenderungan terjadinya peristiwa $\mathrm{y}=1$ pada kategori $\mathrm{x}=0$ (Nachrowi dan Usman, 2002)

\section{DATA YANG DIGUNAKAN}

Unit analisis dalam penelitian ini adalah penduduk Provinsi Jawa Barat yang berusia 15 tahun ke atas, yang berdasarkan data cross section hasil Survei Penduduk antar Sensus (SUPAS) tahun 2015 yang berjumlah 181.238 responden. Konsep penduduk yang digunakan dalam penelitian ini merupakan konsep dari Badan Pusat Statistik (BPS) karena menggunakan data yang dikumpulkan oleh BPS.

Variabel respons yang digunakan adalah status migrasi penduduk berusia 15 tahun ke atas yang dibedakan menjadi dua kategori, yaitu:

1. penduduk dengan status bermigrasi, dan

2. penduduk dengan status tidak bermigrasi.

Variabel penjelas yang digunakan dalam penelitian ini terbagi menjadi variabel individual dan variabel kontekstual. Variabel individual mencakup informasi responden mengenai jenis kelamin, status perkawinan, tingkat pendidikan tertinggi yang ditamatkan, dan juga akses informasi. Sedangkan variabel kontekstual mencakup informasi wilayah (kabupaten) berupa Tingkat Pengangguran Terbuka (TPT), kepadatan penduduk, dan juga Upah Minimun Kab/Kota (UMK).

\section{APLIKASI REGRESI LOGISTIK MULTILEVEL}

Hasil Estimasi Parameter Model Regresi Logistik Multilevel Biner Dengan Random Intercept Pada Status Migrasi Penduduk Berusia 15 Tahun Ke Atas Di Provinsi Jawa Barat

Berdasarkan hasil pengolahan data SUPAS 2015 dengan menggunakan bantuan software Stata/MP versi 13, diperoleh hasil sebagai berikut: 
1. LR test vs. Logistic Regression: $\operatorname{chibar} 2(01)=28.916,36>$ chibar2 $=0,0000$

2. Log Likelihood (null model) $=-79.289,731$

3. Log Likelihood (conditional model) $=-72.470,398$

4. $\mathrm{ICC}=0,22362$

Tabel 1. Hasil estimasi parameter model regresi logistik biner multilevel dengan random intercept pada status migrasi penduduk berusia 15 tahun ke atas

\begin{tabular}{|c|c|c|c|c|c|}
\hline Variabel & Koefisien $(\mathbf{\gamma})$ & Standar Error & Wald (Z) & p-value & Odds Ratio \\
\hline (1) & $(2)$ & (3) & (4) & (5) & (6) \\
\hline \multicolumn{6}{|c|}{ Variabel Indivudual } \\
\hline Jenis Kelamin & -0.0165 & 0.0135 & -1.23 & 0.220 & 0.9836 \\
\hline Status Perkawinan & -1.1936 & 0.0172 & -69.59 & $0.000^{*}$ & 0.3031 \\
\hline \multicolumn{6}{|l|}{ Pendidikan } \\
\hline s.d SMP & 0.5283 & 0.0200 & 26.37 & $0.000^{*}$ & 1.6959 \\
\hline s.d SMA/K & 1.1005 & 0.0187 & 58.85 & $0.000^{*}$ & 3.0056 \\
\hline Lebih dari SMA/K & 1.6118 & 0.0244 & 66.18 & $0.000^{*}$ & 5.0117 \\
\hline Akses Informasi & 0.5759 & 0.0210 & 27.39 & $0.000^{*}$ & 1.7788 \\
\hline \multicolumn{6}{|c|}{ Variabel Kontekstual } \\
\hline TPT & -0.1066 & 0.0535 & -1.99 & $0.046^{*}$ & 0.8988 \\
\hline Kepadatan Penduduk & 0.1161 & 0.0237 & 4.90 & $0.000^{*}$ & 1.1231 \\
\hline UMK & 0.6268 & 0.2010 & 3.12 & $0.002^{*}$ & 1.8715 \\
\hline _Constanta & -3.0232 & 0.4309 & -7.02 & 0.000 & 0.0486 \\
\hline
\end{tabular}

Keterangan: *) signifikan pada tingkat kepercayaan sebesar $95 \%$

Sehingga persamaan regresi logistik biner multilevel (dengan random intercept) untuk status migrasi penduduk berusia 15 tahun ke atas adalah:

$$
\begin{aligned}
\ln \left[\frac{\pi_{i j}}{1-\pi_{i j}}\right]=- & 3.0232-0.0165 \mathrm{JK}-1.1936 \text { SKawin }{ }^{*}+0.5283 \text { Pendidikan } 1^{*}+1.1005 \text { Pendidikan } 2^{*} \\
& +1.6118 \text { Pendidikan } 3^{*}+0.5759 \text { AksInf }^{*}-0.1066 \text { TPT }^{*}+0.1161 \text { Kepadatan }^{*} \\
& +0.6268 \text { UMK }^{*}
\end{aligned}
$$

Keterangan: *) signifikan pada tingkat kepercayaan sebesar $95 \%$

\section{Hasil Pengujian Signifikansi Random Effect}

Hasil pengujian yang dilakukan pada penelitian ini menunjukkan bahwa diperoleh nilai LR test pada null model yang mengikuti distribusi Chi-square sebesar 28.916,36, dan p-value sebesar 0,0000. Berdasarkan persamaan (1), diperoleh nilai $\mathrm{X}_{(0,05,1)}$ sebesar 3,84 , berarti LR lebih besar dari $\mathrm{X}^{2}(0,05,1)$. Sehingga dapat diambil keputusan bahwa Ho ditolak, karena terdapat random effect yang signifikan pada status migrasi. Hal ini memberikan arti bahwa penggunaan model regresi logistik multilevel (model logistik dengan random effect) lebih baik daripada model regresi logistik biasa dalam menganalisis status migrasi penduduk berusia 15 tahun ke atas.

\section{Intraclass Correlation Coefficient (ICC)}

Hasil dari pengolahan data SUPAS 2015 menggunakan persamaan (2) diperoleh hasil berupa nilai ICC dari null model sebesar 0,22362. Angka ini menunjukkan bahwa 22,362 persen variasi migrasi penduduk berusia 15 tahun keatas di Provinsi Jawa Barat dipengaruhi oleh perbedaan karakteristik individu-individu yang ada di tiap kabupaten/kota. 


\section{Uji Parameter Secara Simultan (Uji G)}

Hasil olah data SUPAS 2015 menunjukkan keluaran (output) sebagai berikut:

LO=-79 289,731; Lp=-72 470,398; $\quad X_{(0,05 ;)}^{2}=14,07 ;$

$G=-2 \operatorname{Ln}\left[\frac{L_{0}}{L_{\mathrm{p}}}\right]=-2 \operatorname{Ln}\left[\frac{-79.289,731}{-72.470,398}\right]=(158.579,462-144.940,796)=13.638,666$

Proses penghitungan yang telah dilakukan dengan menggunakan persamaan (3) memperoleh hasil berupa nilai uji G sebesar 13.638,666, dimana nilai ini jauh lebih besar dibandingkan $X_{(0,05 ;)}^{2}$ yang hanya sebesar 14,07. Sehingga dapat diambil keputusan bahwa Ho ditolak, atau dengan kata lain minimal terdapat satu variabel penjelas yang memengaruhi variabel status migrasi penduduk berusia tahun ke atas di Provinsi Jawa Barat.

\section{Uji Parameter Secara Parsial (Uji Wald)}

Dari hasil pengolahan data SUPAS 2015 menggunakan persamaan (4) diketahui bahwa variabel penjelas berupa status perkawinan, tingkat pendidikan tertinggi, akses informasi, Tingkat Pengangguran Terbuka, kepadatan penduduk, dan Upah Minimum Kabupaten/Kota yang digunakan dalam model memiliki nilai mutlak uji Wald $(|Z|)$ yang lebih besar dibandingkan nilai $Z_{\mathrm{a} / 2}$ yang digunakan $\left(Z_{(0,025)}=1,96\right)$. Sehingga dapat diambil keputusan bahwa Ho ditolak, atau dengan kata lain variabel-variabel penjelas tersebut memengaruhi variabel status migrasi penduduk berusia 15 tahun ke atas secara parsial.

\section{Pengujian Hipotesis dan Interpretasi Odds Ratio}

Berikut merupakan hasil pengujian hipotesis statistik yang dilakukan dengan uji Wald dari persamaan (4) dalam model regresi logistik biner multilevel:

1. Jenis Kelamin

Berdasarkan Tabel 1, terlihat bahwa diperoleh nilai uji Wald untuk variabel jenis kelamin sebesar -1,23. Dengan menggunakan tingkat kepercayaan sebesar 95 persen, maka nilai mutlak uji Wald lebih kecil dibandingkan dengan $Z_{(0,025)}=1,96$ sehingga diputuskan bahwa $\mathrm{H}_{0}$ diterima. Sehingga dapat disimpulkan bahwa variabel jenis kelamin tidak signifikan dalam memengaruhi status migrasi penduduk berusia 15 tahun ke atas di Provinsi Jawa Barat.

\section{Status Perkawinan}

Berdasarkan Tabel 1, terlihat bahwa diperoleh nilai uji Wald untuk variabel status perkawinan sebesar -69,59. Dengan menggunakan tingkat kepercayaan sebesar 95 persen, maka nilai mutlak uji Wald lebih besar dibandingkan dengan $Z_{(0,025)}=1,96$ sehingga diputuskan bahwa $\mathrm{H}_{0}$ ditolak. Sehingga dapat disimpulkan bahwa variabel status perkawinan signifikan dalam memengaruhi status migrasi penduduk berusia 15 tahun ke atas di Provinsi Jawa Barat. Variabel status perkawinan dengan kategori belum kawin memiliki estimasi koefisien regresi $(\hat{\gamma})$ bernilai negatif, yaitu -1,1936. Tanda negatif pada koefisien regresi ini menunjukkan bahwa penduduk berusia 15 tahun ke atas dengan status belum kawin cenderung untuk melakukan migrasi lebih sedikit dibandingkan penduduk berusia 15 tahun ke atas dengan status kawin/pernah kawin. Dengan menggunakan persamaan (5) diperoleh nilai odds ratio sebesar 0,31 , nilai ini menunjukkan bahwa penduduk berusia 15 tahun ke atas dengan status belum kawin memiliki kecenderungan untuk melakukan migrasi 0,31 kali lebih sedikit dibandingkan dengan penduduk berusia 15 tahun ke atas dengan status kawin/pernah kawin.

3. Tingkat Pendidikan Tertinggi

Dari Tabel 1 diperoleh nilai uji Wald untuk variabel tingkat pendidikan tertinggi dengan kategori sampai dengan SMP sebesar 26,37, dengan kategori sampai dengan SMA/K sebesar 58,85 , dan dengan kategori lebih dari SMA/K sebesar 66,18. Dengan menggunakan tingkat kepercayaan sebesar 95 persen, maka nilai mutlak uji Wald untuk tiap kategori lebih besar dibandingkan dengan $Z_{(0,025)}=1,96$ sehingga diputuskan bahwa $H_{0}$ ditolak. Sehingga dapat disimpulkan bahwa variabel tingkat pendidikan tertinggi signifikan dalam memengaruhi status migrasi penduduk berusia 15 tahun ke atas di Provinsi Jawa Barat. Variabel tingkat pendidikan tertinggi dengan kategori sampai dengan SMP memiliki estimasi koefisien regresi $(\hat{\gamma})$ bernilai positif, yaitu 0,5283. Tanda positif pada koefisien regresi ini menunjukkan bahwa penduduk berusia 15 tahun ke atas dengan tingkat pendidikan tertinggi sampai dengan SMP 
cenderung untuk melakukan migrasi lebih banyak dibandingkan penduduk berusia 15 tahun ke atas dengan tingkat pendidikan tertingi sampai dengan SD. Dengan menggunakan persamaan (5) diperoleh nilai odds ratio sebesar 1,69 yang menunjukkan bahwa penduduk berusia 15 tahun ke atas dengan tingkat pendidikan tertinggi sampai dengan SMP memiliki kecenderungan untuk melakukan migrasi 1,69 kali lebih banyak dibandingkan dengan penduduk berusia 15 tahun ke atas dengan tingkat pendidikan tertinggi sampai dengan SD. Variabel tingkat pendidikan tertinggi dengan kategori sampai dengan SMA/K memiliki estimasi koefisien regresi ( $\hat{\gamma})$ bernilai positif, yaitu 1,1005. Tanda positif pada koefisien regresi ini menunjukkan bahwa penduduk berusia 15 tahun ke atas dengan tingkat pendidikan tertinggi sampai dengan SMA/K cenderung untuk melakukan migrasi lebih banyak dibandingkan penduduk berusia 15 tahun ke atas dengan tingkat pendidikan tertingi sampai dengan SD. Nilai odds ratio sebesar 3,01 menunjukkan bahwa penduduk berusia 15 tahun ke atas dengan tingkat pendidikan tertinggi sampai dengan SMA/K memiliki kecenderungan untuk melakukan migrasi 3,01 kali lebih banyak dibandingkan dengan penduduk berusia 15 tahun ke atas dengan tingkat pendidikan tertinggi sampai dengan SD. Variabel tingkat pendidikan tertinggi dengan kategori lebih dari SMA/K memiliki estimasi koefisien regresi $(\hat{\gamma})$ bernilai positif, yaitu 1,6118. Tanda positif pada koefisien regresi ini menunjukkan bahwa penduduk berusia 15 tahun ke atas dengan tingkat pendidikan tertinggi lebih dari SMA/K cenderung untuk melakukan migrasi lebih banyak dibandingkan penduduk berusia 15 tahun ke atas dengan tingkat pendidikan tertingi sampai dengan SD. Nilai odds ratio sebesar 5,01 menunjukkan bahwa penduduk berusia 15 tahun ke atas dengan tingkat pendidikan tertinggi lebih dari SMA/K memiliki kecenderungan untuk melakukan migrasi 5,01 kali lebih banyak dibandingkan dengan penduduk berusia 15 tahun ke atas dengan tingkat pendidikan tertinggi sampai dengan SD.

\section{Akses Informasi}

Dari Tabel 1, terlihat bahwa dengan menggunakan persamaan (4) diperoleh nilai uji Wald untuk variabel akses infromasi sebesar 27,39. Dengan menggunakan tingkat kepercayaan sebesar 95 persen, maka nilai mutlak uji Wald lebih besar dibandingkan dengan $Z_{(0,025)}=1,96$ sehingga diputuskan bahwa $\mathrm{H}_{0}$ ditolak. Hasil tersebut menunjukkan bahwa data dalam penelitian ini mendukung hipotesis penelitian. Sehingga dapat disimpulkan bahwa variabel akses informasi signifikan dalam memengaruhi status migrasi penduduk berusia 15 tahun ke atas di Provinsi Jawa Barat. Variabel akses informasi dengan kategori mendapat akses informasi memiliki estimasi koefisien regresi $(\hat{y})$ bernilai positif, yaitu 0,5759. Tanda positif pada koefisien regresi ini menunjukkan bahwa penduduk berusia 15 tahun ke atas yang mendapat akses informasi cenderung untuk melakukan migrasi lebih banyak dibandingkan penduduk berusia 15 tahun ke atas yang tidak mendapat akses informasi. Dengan persamaan (5) nilai odds ratio sebesar 1,78 menunjukkan bahwa penduduk berusia 15 tahun ke atas yang mendapat akses informasi memiliki kecenderungan untuk melakukan migrasi 1,78 kali lebih banyak dibandingkan dengan penduduk berusia 15 tahun ke atas yang tidak mendapat akses informasi.

\section{Tingkat Pengangguran Terbuka}

Berdasarkan Tabel 1, terlihat bahwa diperoleh nilai uji Wald untuk variabel tingkat pengangguran terbuka sebesar -1,99. Dengan menggunakan tingkat kepercayaan sebesar 5 persen, maka nilai mutlak uji Wald lebih besar dibandingkan dengan $Z_{(0,025)}=1,96$ sehingga diputuskan bahwa HO ditolak. Hasil tersebut menunjukkan bahwa data dalam penelitian ini mendukung hipotesis penelitian. Sehingga dapat disimpulkan bahwa variabel tingkat pengangguran terbuka signifikan dalam memengaruhi status migrasi penduduk berusia 15 tahun ke atas di Provinsi Jawa Barat. Tingkat Pengangguran Terbuka (TPT) yang diperoleh dari hasil estimasi model regresi logistik multilevel memiliki koefisien $(\hat{\gamma})$ yang bernilai negatif $(-$ 0,1066). Hal ini menunjukkan bahwa semakin tinggi TPT yang dimiliki oleh suatu daerah, maka kecenderungan penduduk berusia 15 tahun ke atas untuk melakukan migrasi ke daerah tersebut akan semakin rendah. Nilai odds ratio sebesar 0,8988 menunjukkan bahwa setiap kenaikan TPT sebesar satu persen, maka kecenderungan penduduk berusia 15 tahun ke atas untuk melakukan migrasi akan berkurang sebesar 0,8988 kali.

\section{Kepadatan Penduduk}

Berdasarkan Tabel 1, terlihat bahwa diperoleh nilai uji Wald untuk variabel tingkat kepadatan penduduk sebesar 4,90. Dengan menggunakan tingkat kepercayaan sebesar 5 persen, maka nilai mutlak uji Wald lebih besar dibandingkan dengan $Z_{(0,025)}=1,96$ sehingga diputuskan bahwa HO ditolak. Hasil tersebut menunjukkan bahwa data dalam penelitian ini mendukung 
hipotesis penelitian. Sehingga dapat disimpulkan bahwa variabel tingkat kepadatan penduduk signifikan dalam memengaruhi status migrasi penduduk berusia 15 tahun ke atas di Provinsi Jawa Barat. Kepadatan penduduk yang diperoleh dari hasil estimasi model regresi logistik multilevel memiliki koefisien $(\hat{\gamma})$ yang bernilai positif $(0,1161)$. Hal ini menunjukkan bahwa semakin tinggi tingkat kepadatan penduduk yang dimiliki oleh suatu daerah, maka kecenderungan penduduk berusia 15 tahun ke atas untuk melakukan migrasi ke daerah tersebut juga semakin tinggi. Dengan persamaan (5) diperoleh nilai odds ratio sebesar 1,1231 menunjukkan bahwa setiap kenaikan angka kepadatan penduduk sebesar seribu jiwa/ $\mathrm{km} 2$, maka kecenderungan penduduk berusia 15 tahun ke atas untuk melakukan migrasi akan bertambah sebesar 1,1231 kali.

\section{Upah Minimum Kabupaten/Kota}

Berdasarkan Tabel 1, terlihat bahwa diperoleh nilai uji Wald untuk variabel upah minimum kabupaten/kota sebesar 3,12. Dengan menggunakan tingkat kepercayaan sebesar 5 persen, maka nilai mutlak uji Wald lebih besar dibandingkan dengan $Z_{(0,025)}=1,96$ sehingga diputuskan bahwa HO ditolak. Hasil tersebut menunjukkan bahwa data dalam penelitian ini mendukung hipotesis penelitian. Sehingga dapat disimpulkan bahwa variabel upah minimum kabupaten/kota signifikan dalam memengaruhi status migrasi penduduk berusia 15 tahun ke atas di Provinsi Jawa Barat. Upah Minimum Kabupaten/Kota (UMK) yang diperoleh dari hasil estimasi model regresi logistik multilevel memiliki koefisien $(\hat{\gamma})$ yang bernilai positif $(0,6268)$. Hal ini menunjukkan bahwa semakin tinggi UMK yang dimiliki oleh suatu daerah, maka kecenderungan penduduk berusia 15 tahun ke atas untuk melakukan migrasi ke daerah tersebut juga semakin tinggi. Dengan persamaan (5) diperoleh nilai odds ratio sebesar 1,87 yang menunjukkan bahwa setiap kenaikan UMK sebesar satu juta rupiah, maka kecenderungan penduduk berusia 15 tahun ke atas untuk melakukan migrasi akan bertambah sebesar 1,87 kali.

\section{KESIMPULAN DAN SARAN}

\section{Kesimpulan}

Status migrasi penduduk berusia 15 tahun ke atas di Provinsi Jawa Barat pada tahun 2015 dipengaruhi secara signifikan oleh variabel-variabel individual berupa status perkawinan, tingkat pendidikan tertinggi, akses informasi, dan variabel-variabel kontekstual berupa Tingkat Pengangguran Terbuka (TPT), kepadatan penduduk, dan Upah Minimum Kabupaten/Kota (UMK).

Penduduk berusia 15 tahun ke atas di Provinsi Jawa Barat pada tahun 2015 lebih cenderung melakukan migrasi jika memiliki status kawin/pernah kawin, memiliki tingkat pendidikan tertinggi lebih dari SMA/K, dan mendapat akses informasi. Selain itu, penduduk berusia 15 tahun ke atas ini akan cenderung melakukan migrasi lebih banyak menuju daerah dengan tingkat pengangguran terbuka yang rendah, kepadatan penduduk yang tinggi, dan upah minimum kabupaten/kota yang tinggi.

\section{Saran}

Untuk menyukseskan program pemerataan penduduk, sebaiknya pemerintah membuka lapangan pekerjaan dan mengupayakan pemerataan upah serta pemerataan pembangunan agar kesenjangan antarwilayah dapat berkurang.

Untuk masyarakat, disarankan supaya mempertimbangkan pemilihan daerah tujuan bermigrasi agar mengurangi kemungkinan terjadinya persebaran penduduk yang tidak merata. Selain itu, masyarakat juga disarankan untuk meningkatkan kualitas dirinya sebelum melakukan migrasi agar mengurangi dampak negatif yang timbul dari migrasi, seperti meningkatkan pendidikan dan keterampilan agar di tempat tujuan migrasi tidak menjadi pengangguran.

Untuk penelitian selanjutnya, disarankan supaya menambahkan variabel_variabel lain yang mungkin juga berpengaruh terhadap status migrasi penduduk berusia 15 tahun ke atas baik pada level individual maupun kontekstual. Misalnya variabel PDRB yang belum dimasukkan dalam penelitian ini karena adanya keterbatasan data. Selain itu, disarankan supaya 


\section{Athiyyah Nafsu'l Muthmainnah, Budyanra}

digunakan metode analisis statistik lainnya yang juga dapat digunakan untuk menganalisis status migrasi penduduk berusia 15 tahun ke atas.

\section{DAFTAR PUSTAKA}

Abdullah, Syahrifin. (1996). "FaktorFaktor Penentu Status Migrasi Penduduk Propinsi Lampung" [Tesis]. Depok: Program Pascasarjana Kependudukan dan Ketenagakerjaan Universitas Indonesia.

BPS. (2012). Penduduk Indonesia Hasil Sensus Penduduk 2010. Jakarta: BPS.

BPS. (2015). Jawa Barat dalam Angka (Jawa Barat in Figures) 2015. Jakarta: BPS.

BPS. (2016). Penduduk Indonesia Hasil Survei Penduduk Antar Sensus 2015.Jakarta: BPS.

BPS. (2016). Jawa Barat dalam Angka (Jawa Barat in Figures) 2016. Jakarta:BPS.

Darmawan, B., dan Chotib. (2007). Perkiraan Pola Migrasi Antar Provinsi di Indonesia berdasarkan "Indeks Ketertarikan Ekonomi". Parallel Session IIIC: Poverty, Population and Health. Depok: Lembaga Demografi FEUI.

Dohar, Ahmad. (1999). Analisis Kecenderungan Migrasi Tenaga Kerja ke Propinsi Jawa Barat (Analisis Data SUPAS Tahun 1995). [Tesis]. Depok: Program Pascasarjana Program Studi Kependudukan dan Ketenagakerjaan, Universitas Indonesia.

Ehrenberg, R.G and Smith, R.S (2012). Modern Labor Economy:Theory and Public Policy. $11^{\text {th }}$ edition. Pearson education.Inc. New York.

Ezra, Markos dan Gebre-Egziabher Kiros. (2001). Desa Out-migration in the Drought Phone Areas of Ethiopia: A Multilevel Analysis. International Migration Review Journal 35(3), pp. 749-771.

Fujita,M; Krugman,P; Venables,A.J (1999). The Spatial Economy:Cities, Regions and International Trade. The MIT Press. Cambridge, Massachusetts.

Goldstein, Harvey. (1995). Multilevel Statistical Models. London: Arnold London.

Hia, Supriadi. (2015). Pengaruh Perekonomian Kabupaten/Kota di Jawa Barat terhadap Migrasi Tenaga Kerja Tahun 2010 dengan Pemodelan Geographically Weighted Regression. [Skripsi]. Jakarta: STIS.

Hosmer, David W. Dan Stainley Lemeshow. (1989). Applied Logistic Regression. New York: Wiley.

Hox, Joop J. (2010). Multilevel Analysis (Techniques and Applications): Second Edition. New York: Routledge.

Laksono, Hani dan Eko Budi Santoso. (2012). Penarik Migrasi di Kota Surabaya berdasarkan Preferensi Penduduk Migran. Jurnal Teknik Pomits 1(2), pp.1-4.

Lee, Everett S. (1966). A Theory of Migration. Demography 3(1), pp. 47-57.

Liu, Yanyan dan Futoshi Yamauchi. (2013). "Population Density, Migration, and the Returns to Human Capital and Land. IFPRI Discussion Paper 01271".Dipetik Juli 7, 2016 dari http://www.sciencedirect.com/science/article/pii/S0306919214000773.

Mc.Connel, C.R; Brue,S.L (1995. Mobility, Migration and Efficiency. In Contemporary Labour Economics, $4^{\text {th }}$ ed. New York: McGraw-Hill.

Mantra, Ida Bagoes. (2000). Demografi Umum. Yogyakarta: Pustaka Pelajar.

Munir, Rozi (1981). Dasar-dasar Demografi Migrasi. Jakarta: Lembaga Demografi UI.

Muto, Megumi. (2010). "The Impacts of Mobile Phone and Personal Networks on Migration: Evidence from Uganda". Dipetik Juli 7, 2016 dari http://www.csae.ox.ac.uk/conferences/2010edia/papers/221-Muto.pdf.

Saepudin, Asep. (2007). Analisis Faktor-Faktor yang Mempengaruhi Migrasi Risen Tenaga Kerja Masuk ke Wilayah Bogor, Depok, Tangerang dan Bekasi (Bodetabek) (Analisis Data SUPAS 2005). [Tesis]. Depok: Program Studi Kependudukan dan Ketenagakerjaan Program Pascasarjana Universitas Indonesia.

Sorra, J.S. \& Dyer, N. (2010). Multilevel psychometric properties of the AHRQ hospital survey on patient safety culture. BMC Health Services Research 2010, 10:19.

Surat Keputusan Gubernur Jawa Barat Nomor: 561/ Kep. 1581-Bangsos/ 2014 Tentang Upah Minimum Kabupaten/Kota di Jawa Barat Tahun 2015.

Zopf, P. E. (1984). Population: An Introduction to Social Demography $1^{\text {st }}$ edition. Mayfield Publishing Company. 